\title{
"NOTÓRIA ESPECIALIZAÇÃO" COMO REQUISITO PARA A INEXIGIBILIDADE DE LICITAÇÃO PARAA CONTRATAÇÃO DIRETA PELO PODER PÚBLICO
}

\section{"SPECIAL RECOGNITION" AS A REQUIREMENT FOR THE UNENFORCEABILITY OF THE BID PROCESS FOR DIRECT HIRING BY THE PUBLIC ADMINISTRATION}

\section{Isabel Helena Almeida de Albuquerque ${ }^{1}$}

Resumo: $\mathrm{O}$ presente artigo científico será focado nas hipóteses de contratação direta por meio da Administração Pública. Questiona-se a legalidade desta contratação e se ela está inserida dentro dos princípios que regem a Administração Pública e o processo licitatório, este responsável pela contratação, alienação de bens, obras e serviços do meio público. A hipótese do trabalho baseia-se na relação que o princípio da obrigatoriedade e as exceções de hipótese de licitação, qual a forma que a lei abrange tais exceções. $\mathrm{O}$ artigo será dividido em três capítulos, que abordam a administração pública e seus aspectos gerais, bem como a Lei de Licitações, Lei n. 8.666/93; a dispensa e inexigibilidade da licitação, o princípio da obrigatoriedade e as hipóteses de contratação direta. Por fim, a notória especialização como requisito para a contratação direta, segundo art. 25 da Lei de Licitações.
$\mathrm{O}$ método de abordagem da pesquisa será o dialético, realizado de maneira comparativa e jurídica por meio de consulta ao acervo de biblioteca e pessoais, bem como sites especializados na Internet.

Palavras-chave: Lei de licitações. Hipóteses de contratação direta. Dispensa e inexigibilidade. Princípio da legalidade. Administração pública.

Abstract: The article that follows bellow will be focused on the hypothesis of the direct hiring by the Public Administration. The focus of this research is to question the legality of those direct hiring's and if the process is under the regime of principles, which builds the Public Administration and the bidding process. The bidding process is responsible for the hiring, disposal of assets, construction works and services of the public carrier. The hypothesis of the article is based on the obligation 
of the public carrier. The hypothesis of the article is based on the obligation principle and the exceptions that the bid process cover. The article is divided in three parts: the study of the Public Administration and its general aspects, the obligation principle and the hypotheses of direct hiring and finally, this work analyzes the special recognition as a requirement of the direct hiring, based on article 25 of the Bidding Law
(8666/93 Law). The approach method will be the dialectical and will be done by comparison and legal search through the CESUSC's Library archive, as well as, specialized sites on the Internet.

Keywords: Bidding Process. Hypotheses of Direct Hiring. Dismissal or Unenforceability of Bid Process. Legality Principle. Public Administration.

\section{INTRODUÇÃ̃O}

O presente artigo irá abordar as hipóteses de contratação direta pela Administração Pública, sendo elas, os casos de dispensa e inexigibilidade do processo licitatório. Colocando em questionamento, a legalidade de tais contratações, quais as circunstâncias que a lei prevê.

O espaço de estudo foi delimitado a partir da decisão proferida pelo Superior Tribunal de Justiça em 2008, dentro do Julgado Recurso Especial no 488.842 - SP (2002/0163048-3), a sessão teve como relator o Ministro João Otávio de Noronha. Atualmente o processo está na Suprema Corte, com a relatoria do Ministro Dias Toffoli, aguardando decisão. Diante disso, todos os julgados abordados na quarta seção, são de 2008 em diante.

Dessa forma, a hipótese do artigo diz respeito ao princípio da obrigatoriedade, o qual assegura a contratação por meio de Licitação. E, além disso, sua forte ligação com o princípio da isonomia que prevê a melhor vantagem em prol da administração pública.

A grande discussão fica em torno das contratações diretas, quando a licitação é inexigível, pois os requisitos para que o objeto da licitação seja enquadrado nesta hipótese são de natureza singular, por exemplo, serviços técnicos profissionais.

Primeiramente, é abordada a Administração Pública, seus 
aspectos gerais, como é constituída e os princípios que a regem. Após a Lei de Licitações, n. 8.666/93, a qual institui os requisitos principais e as normas para a contratação de serviços e aquisição de bens pelos entes da Administração Pública, bem como os princípios que regem o procedimento.

Ademais, são expostas as hipóteses de contratação direta, a dispensa e a inexigibilidade da Licitação Pública. Abordam-se os três artigos da Lei n. 8.666/93 (17, 24 e 25) e suas respectivas condições e rol exemplificativos.

E assim, por último, explana-se a notória especialização, o principal requisito para a condição de inexigibilidade, e também, a decisão majoritária do Superior Tribunal de Justiça, tanto positiva quanto negativamente.

A justificativa do trabalho se baseia na discussão atual do cenário político-administrativo conturbado pela corrupção e em vários níveis da sociedade o estudo de processos licitatórios nos mostra inúmeros problemas desde a abertura do edital até o seu fim, sendo de extrema relevância que seja estudado e debatido todos os princípios que regem a contratação licitatória e direta e se esta realmente não afeta princípios da Administração Pública, bem como os princípios que regem a Licitação, que são os descritos no art. 3 da Lei n. 8.666, de 1993, que tratam da legalidade, impessoalidade, moralidade, igualdade, publicidade, probidade administrativa, da vinculação ao instrumento convocatório e do julgamento objetivo.

\section{ADMINISTRAÇÃO PÚBLICA}

A administração engloba quatro funções, segundo a definição de Richard L. Daft (2010, p. 06-08), “administração é $\mathrm{o}$ atingimento das metas organizacionais de modo eficiente $\mathrm{e}$ eficaz por meio do planejamento, organização, liderança e controle dos recursos organizacionais". 
Segundo a autora Maria Sylvia Zanella Di Pietro (2010, p. 44):

Administrar significa não só prestar serviço executá-lo como, igualmente, dirigir, governar, exercer a vontade com o objetivo de obter um resultado útil e que até, em sentido vulgar, administrar quer dizer traçar programa de ação e executá-lo.

No âmbito público, o conceito de administração segundo o autor Hely Lopes Meirelles (2010, p. 65-66), é o de que "a administração pública é todo aparelhamento do Estado, preordenado à realização de seus serviços, visando à satisfação das necessidades coletivas", ou seja, é a forma de gestão do Estado, de organizar e administrar em todas as instâncias tendo como principal objetivo satisfazer a população.

Diante disso, a Constituição Federal de 1988, na redação de seu art. 37, caput:

Art. 37. A administração pública direta e indireta de qualquer dos Poderes da União, dos Estados, do Distrito Federal e dos Municípios, obedecerá aos princípios da legalidade, impessoalidade, moralidade, publicidade e eficiência [...] (BRASIL, 1988).

A administração pública é organizada em direta e indireta. A administração direta é a "que se constitui dos serviços integrados na estrutura administrativa da Presidência da República e dos Ministérios" e a indireta "é a que compreende as seguintes categorias de entidades dotadas de personalidade jurídica própria: a) Autarquias; b) Empresas Públicas; c) Sociedade de Economia Mista; d) Fundações Públicas", segundo o jurista Celso Bandeira de Mello (2011, p. 156-157).

Com base no artigo supracitado da Constituição Federal, a administração pública obedecerá aos princípios da legalidade, impessoalidade, moralidade, publicidade e eficiência, estes princípios pretendem direcionar a atuação em todas as esferas da Administração Pública. 


\subsection{A Lei de licitações}

Com o funcionamento da Administração Pública tão idealmente estruturado, era preciso saber se funcionaria da mesma forma na prática. Dessa forma, a lei de Licitações (Lei n. 8.666, de 1993) fora criada. De modo que pudesse dar a maior transparência aos atos administrativos.

A palavra "licitação" provém do termo latim "licitatione", que significa arrematar em leilão. A sua história remete à Idade Média, nos Estados Medievais Europeus, onde usavam o sistema chamado "Vela e Prego". Este sistema se baseava na ideia de apregoar-se a obra desejada, enquanto uma vela queimava, sendo esse o tempo de duração. Quando a chama apagava, a obra era arrematada por quem houvesse feito o melhor preço ao Estado (CRETELLA JUNIOR, 1975).

Uma lembrança deste sistema medieval é a modalidade italiana denominada estinzionedi candela vergine, em que ofertas são feitas verbalmente enquanto se acendem três velas, uma após a outra. Extinta a terceira e última vela, sem nenhum lance, a licitação é declarada deserta; caso contrário, acende-se uma quarta vela, e assim sucessivamente, pois, para que se possa conceder o objeto do certame, é obrigatório que uma vela tenha ardido por inteiro sem nenhum lance superior precedente. (DI RENZO, 1969, p. 80 apud MEIRELLES, 1999, p. 25)

A Constituição Federal de 1988 representou um evidente progresso na instituição e democratização da administração pública. Sendo assim, a partir de 1988, a licitação recebeu condição de princípio constitucional, de observância obrigatória pela Administração Pública direta e indireta, de todos os poderes da União, Estados, Distrito Federal e Municípios.

Dessa forma, ao analisar o disposto no art. 37, XXI da Constituição Federal, é possível observar que a obrigatoriedade em licitar é princípio constitucional, apenas sendo dispen- 
sada ou inexigida nos casos expressamente previstos em lei.

Celso Antônio Bandeira de Mello (1999, p. 371) define a licitação como um "certame que as entidades governamentais devem promover e no qual abrem disputa entre os interessados em com elas travar determinadas relações de conteúdo patrimonial, para escolher a proposta mais vantajosa às conveniências públicas".

Existem várias modalidades no processo licitatório - concorrência, tomada de preços, convite, concurso, leilão -, é um procedimento administrativo que cada dia que passa atualiza e moderniza sua prática, pois visa o bem maior, que é propiciar ao Poder Público, as melhores condições para os seus contratos.

Como exemplo dessa modernização, cita-se o Regime Diferenciado de Contratação, instituído pela Lei n. 12.464, de 04 de agosto de 2011, criado para proporcionar as contratações em virtude da realização da Copa do Mundo e das Olimpíadas no Brasil e que se consolida como mais uma possibilidade para a Administração Pública.

A licitação é, na verdade, uma sucessão organizada de atos, como o edital ou convite, verificação de idoneidade ou habilitação, julgamentos e adjudicação, obedecendo rigorosamente ao estabelecido em lei e não admitindo a discricionariedade em sua realização. Uma forma de combate a parcialidade do administrador público. Salvo exceção prevista em lei, que autorize preferências técnicas e opções administrativas de conveniência e oportunidade.

\section{DISPENSA E INEXIGIBILIDADE DA LICITAÇÃO}

A obrigatoriedade da Licitação incita em uma contratação ou prestação de serviço mais vantajosa ao interesse público.

[...] a licitação pública é obrigatória em tributo aos princí- 
pios regentes da Administração Pública, que visam a proteger o interesse público de atos imorais, marcados pela pessoalidade e, com destaque, que imputem aos membros da coletividade tratamento discriminatório apartado da razoabilidade. (NIEBUHR, 2015, p. 123)

Contudo, o princípio constitucional de licitar não tem valor absoluto, ou seja, acaba sendo trabalhado com outros princípios presentes no mundo do Direito. Dessa forma, há alguns casos previstos pelo legislador que promovem o afastamento do princípio da licitação, cedendo o espaço ao princípio da economicidade ou da segurança nacional, ou ainda, para garantir o interesse público, a respectiva necessidade de o Estado intervir na economia (FERNANDES, 2016, P. 147).

\subsection{Exceções à obrigatoriedade da licitação}

O princípio da obrigatoriedade da licitação impõe que todos os destinatários do Estatuto façam realizar o procedimento antes de contratarem obras e serviços. Contudo, a lei não poderia deixar de ressalvar algumas hipóteses que, pela sua particularidade, não se compatibilizam com o rito e a demora do processo licitatório. (CARVALHO FILHO, 2013, p. 250)

Sobre isso, o disposto no inciso XXI do art. 37 da Constituição Federal:

Ressalvados os casos especificados na legislação, as obras, serviços, compras e alienações serão contratadas mediante processo de licitação pública que assegure igualdade de condições a todos os concorrentes, com cláusulas que estabeleçam obrigações de pagamento, mantidas as condições efetivas da proposta, nos termos da lei, a qual somente permitirá as exigências de qualificação técnica e econômica, indispensáveis à garantia do cumprimento das obrigações. (BRASIL, 1988)

Tais exceções seriam as dispostas na própria Lei de Licitações, a dispensa e a inexigibilidade, previstas nos arts. 17, 24 e 25. 


\subsubsection{As contratações diretas}

Existem hipóteses em que se admite a contratação direta, sem licitação. Tais casos podem ser divididos em duas categorias, basicamente. Há as hipóteses de inexigibilidade de licitação e as de dispensa de licitação. (JUSTEN FILHO, 2009, p. 383)

Caracteriza-se a dispensa de licitação pela circunstância de que o procedimento poderia ser realizado, ou seja, há possibilidade de competição, porém, em virtude da particularidade do caso, decidiu o legislador que não seria obrigatório, ficando inserida na competência discricionária da Administração a análise e decisão. $\mathrm{O}$ oposto ocorre na inexigibilidade, pois nestes casos se torna inviável a realização do certame, diante do fato que só existe um objeto ou uma pessoa que atenda às necessidades da Administração.

No art. 24 da Lei n. 8.666, de 1993, encontram-se as hipóteses em que a licitação será dispensável. Por outro lado, no art. 17, da citada Lei de Licitações, ficam previstos os casos que em o administrador fica dispensado de licitar. Esses casos de dispensa escapam à discricionariedade administrativa, por serem determinadas em lei. Segundo Hely Meirelles "A licitação dispensada é aquela que a própria lei declarou-a como tal” (1998, p. 242).

Por outro lado, a licitação dispensável "é toda aquela que a Administração poderá dispensar, caso lhe convier.", segundo Hely Meirelles (1998, p. 243). E, existem previstos em lei, vinte e um casos que a permitem (art. 24, I a XXI). Tais hipóteses de dispensa podem ser divididas em quatro categorias: a) em razão do pequeno valor; b) em razão de situações excepcionais; c) em razão do objeto e; d) em razão da pessoa (FIGUEIREDO; FERRAZ, 1994, p. 9).

Por fim, a licitação inexigível é quando há impossibilidade jurídica de competição entre os contratantes (MEIRELLES, 1998, p. 246). Ou seja, o bem ou serviço a ser usufruído pela 
Administração Pública, não tem como ser mensurado tanto por sua natureza específica quanto pelos objetivos sociais visados pela Administração, portanto sua licitação é inviável.

Segundo Jorge Ulisses Jacoby Fernandes (2016, p. 466) "a expressão utilizada (inviável) é salientada pela doutrina pátria para assegurar que se trata de elenco exemplificativo, firmando a assertiva de que os casos registrados não são os únicos."

Os casos que se encaixam na possibilidade de inexigibilidade de licitação são previstas no art. 25 da Lei n. 8.666/93, o qual estabelece as hipóteses (incisos I, II e III) nas quais se impõe a obrigatoriedade de contratação direta por meio da Administração Pública com o particular, sobretudo, pois a realização do procedimento licitatório seria materialmente impossível.

Com enfoque aos serviços técnicos profissionais especializados de natureza singular, o então inciso II do art. 25 da Lei n. $8.666 / 93$, que em seu $\S 1^{\circ}$ discorre quais os elementos necessários para a atribuição do mesmo.

O dispositivo supracitado tem origem no Decreto-lei $\mathrm{n}$. 200/1967 e teve sua redação mantida conforme o Decreto-lei n. 2.300/1986. Ademais, a definição das características pretendidas pela Administração não raro tem servido para estabelecer reservas de mercado, impróprias para um país que ostenta uma dívida social tão grande a ser resgatada, sem referir-se a manifesta afronta ao princípio da isonomia (FERNANDES, 2016, p. 519).

Em relação ao inciso II, é necessária a observação de três requisitos: (i) contratação de serviços técnicos enumerados no art. 13 do mesmo diploma legal; (ii) que os serviços tenham natureza singular, e (iii) que os profissionais ou empresas a serem contratados tenham notória especialização na execução dos serviços a serem prestados. (VELLOSO, 2015)

O primeiro requisito que deve ser observado é o disposto no art. 13 da Lei n. 8.666/93, inciso V:

Art. 13. Para fins desta Lei, consideram-se serviços técni- 
cos profissionais especializados os trabalhos relativos a:

I - estudos técnicos, planejamentos e projetos básicos ou executivos;

II - pareceres, perícias e avaliações em geral;

III - assessorias ou consultorias técnicas e auditorias financeiras ou tributárias;

IV - fiscalização, supervisão ou gerenciamento de obras ou serviços;

V - patrocínio ou defesa de causas judiciais ou administrativas;

VI - treinamento e aperfeiçoamento de pessoal;

VII - restauração de obras de arte e bens de valor histórico.

VIII - (Vetado) (BRASIL, 1988, grifo nosso)

Importante ressaltar que, não necessariamente somente o previsto listados pelo art. 13 serão as hipóteses de inexigibilidade, tendo em vista que a inexigibilidade resulta da inviabilidade de competição, dependente não de disposição legislativa, mas de situação fática (NIEBUHR, 2015, p. 163). Ou seja, o artigo prevê hipóteses exemplificando um leque de outras situações nas quais ficam antecipadas as características de inviabilidade implicitamente.

Sobre a conceituação, também:

Serviços técnicos profissionais especializados, no consenso doutrinário, são os prestados por quem, além da habilitação técnica e profissional - exigida para os serviços técnicos profissionais em geral -, aprofundou-se nos estudos, no exercício da profissão, na pesquisa cientifica, ou através de cursos de pós-graduação ou de estágios de aperfeiçoamentos. (MEIRELLES, 1998, p. 247)

Não definiu a lei o que seria essa "natureza singular" dos serviços técnicos capaz de tornar inexigível o procedimento licitatório para sua contratação. A doutrina procurou suprir a 
omissão legislativa, mas a matéria não está, ainda, pacificada. (VELLOSO, 2015, p. 11)

Sobre isso:

[...] sabe-se que há serviços de natureza comum, cuja prestação exige conhecimento técnico generalizado, que pode perfeitamente ser comparado objetivamente numa licitação pública. Todavia, há certos serviços que demandam primor técnico diferenciado, disposto por poucos, que imprimem neles as suas características pessoais. Trata-se de serviços cuja especialização requerem aporte subjetivo, o toque do especialista, distinto de um para outro, o que qualifica como singular. (NIEBUHR, 2015, p. 164)

No tocante ao terceiro requisito, a notória especialização para a contratação direta de serviços técnico-profissionais, conceitua Joel de Menezes Niebuhr (2015, p. 172):

A expressão notória especialização costuma ser interpretada de molde a exigir alguém bastante conhecido em seu meio, afamado, que goze, como o próprio nome indica, de notoriedade.

Ademais, além dos requisitos, deverá ser observado o preenchimento do requisito legal, a maneira como o mesmo está relacionado com o objeto da contratação. Sobre isso:

Deve-se ter sempre em mente o binômio que faz inexigível a licitação, sendo que, se faltar um dos requisitos (um dos termos ou elementos do binômio), o serviço precisará ser licitado: o primeiro elemento - serviços de natureza singular (aqueles, todos, elencados nos incisos I a VII do art. 13; outros, ainda que a vida das Administrações indica existirem); segundo elemento - contratados com profissionais ou empresas de notória especialização no ramo pertinente ao objeto pretendido, e não em outro ramo.

Se o serviço pretendido é de treinamento de pessoal, não adiantará para a entidade ser a firma em vista especializada em adestramento de cachorros para a polícia de narcotráfico, ou em treinamento de caratê para o serviço secreto. (BOTTINI, RIGOLIN, 1995, p. 271) 
Não obstante, é necessário ressaltar que há necessidade de justificar os casos de dispensa e inexigibilidade.

\section{NOTÓRIA ESPECIALIZAÇÃO COMO REQUISITO DA INEXIGIBILIDADE}

O caput do art. 25 da Lei n. 8.666/93 estabelece os casos em que será inexigível a licitação. "A inexigibilidade ocorre nas hipóteses em que se afigura a inviabilidade de competição, o que, por sua vez, vem a cabo por maneiras distintas.", segundo Joel de Menezes Niebuhr (2015, p. 162).

Entre as hipóteses previstas no art. 25 da Lei de Licitações, n. 8.666/93, encontra-se a contratação de serviços especializados, de natureza singular e munidos de notória especialização.

A notória especialização pode ser considerada como um plus do profissional contratado.

Segundo o art. 25 da lei, exige-se que o contratado seja especializado, é dizer, tenha gabarito para enfrentar e solucionar a contento o desafio colocado. Especialista, segundo o Aurélio, é a pessoa que se consagra com particular interesse e cuidado a certo estudo ou ainda, pessoa que se dedica a um ramo de sua profissão; pessoa que tem habilidade ou prática especial em determinada coisa, ou conhecedor, perito. (MARTINES JÚNIOR, 2004)

Conforme Jorge Ulisses Jacoby Fernandes (2016, p. 550), "[...] insta ressaltar que a notória especialização do futuro contratado deve estar associada ao objeto pretendido pela Administração, e ser suficiente para atender à singularidade imposta pelo interesse público".

\subsection{A inexigibilidade para contratações de serviços jurídicos}

No tocante a inexigibilidade para a contratação de serviços 
jurídicos muito se discute nas Cortes de Contas, bem como no Judiciário, tanto pelo Ministério Público (por ações civis públicas por ato de improbidade administrativa), ou até mesmo do próprio cidadão utilizando-se da ação popular. Entretanto, não há entendimento pacificado acerca do assunto.

Segundo Joel de Menezes Niebuhr (2015, p. 176):

Os serviços de natureza jurídica são prestados por profissionais técnicos especializados, já que requerem o bacharelado em Direito e a inscrição na Ordem dos Advogados do Brasil. Portanto, não são serviços prestados por qualquer profissional, mas só aqueles especialmente qualificados, em vista do que a contratação deles pode fundar-se no inciso II do artigo 25 da Lei no 8.666/93, desde que respeitados os pressupostos $[\ldots]$

A contratação por inexigibilidade dos serviços jurídicos segue as mesmas regras dispostas para os casos de serviços técnicos de natureza singular, isto é, devem ser observados os pressupostos objetivos e subjetivos, bem como justificativa pela Administração Pública.

Quando se trata de contratação de advogado para cuidar de serviço de natureza singular, não há como deixar de exigir, sobretudo, experiência profissional, vale dizer, efetivo exercício da advocacia de forma continuada no setor da especialização, ou exercício de cargos de magistério, da magistratura e nas procuradorias jurídicas estatais, inclusive no Ministério Público, nos quais a matéria ali tenha sido cuidada pelo profissional, do que terá dado mostra mediante a publicação de votos, sentenças, artigos de doutrina e pareceres. (VELLOSO, 2015)

Para a lei, para a contratação de serviços técnico-profissionais, incluindo os de advogado, quando se trata de natureza singular, notória especialização e complexidade e relevância para a Administração Pública, será considerado inexigível a licitação. Por outro lado, caso a atividade não tenha o caráter de unidade, não caberá à inviabilidade de licitação. 
Coerente com o defendido neste trabalho, já tivemos oportunidade de sustentar a possibilidade, atuando pelo Ministério Público de 2. instância, nos autos da AC 207.349.5/000, da 6. Câm. de Direito Público do TJSP, entre outros. Trata-se da contratação de sociedade de advogados notoriamente especializados em Direito Bancário, para ajuizamento de ações de repetição de indébito por pagamento de juros excessivos em operações de antecipação de receita orçamentária (ARO), providência adotada por recomendação do Egrégio Tribunal de Contas. Bem examinada a hipótese, se verificou a presença da singularidade do objeto e a notória especialização da sociedade de advogados contratada. Assim como nesse, em outro seria possível a contratação direta, desde que o Poder Público envolvido possa verificar que os serviços enfocados são técnico-profissional-especializados, igualmente presente a singularidade do objeto. (MARTINES JÚNIOR, 2004)

Além disso, é necessária a observação do previsto no art. 26, da Lei de Licitações, no tocante à justificativa da determinada contratação direta. Sobre isso, Celso Antônio Bandeira de Mello (2014, p. 570):

$\mathrm{O}$ art. 26 determina que as dispensas de licitação previstas nos $\S \S 2^{\circ}$ e $4^{\circ}$ do art. 17 e nos incisos III e ss. do art. 24 (as quais abrangem todos os casos, salvo os pertinentes a dispensas por pequeno valor do objeto), assim como as situações de inexigibilidade [...] deverão ser necessariamente justificados e comunicados dentro em três dias, à autoridade superior, para ratificação e publicação na imprensa oficial no prazo de cinco dias, como condição de eficácia dos atos.

O entendimento jurisprudencial que predomina é que o que define a legalidade da licitação encontra-se no critério da notória especialização, a ausência da mesma torna a contratação ilegítima, podendo em tese, ainda, ser considerada crime capitulado no art. 89 da Lei n. 8.666/93.

Observados os acórdãos do Superior Tribunal de Justiça, é inerente que a conduta majoritária prevalece no sentido de jul- 
gar procedente o que consta como contratação de advogados pelo Poder Público, salvo exceção que não seja constituída a notória especialização, seja como advogado ou como escritório de advocacia, bem como a prévia justificativa consoante o art. 26 da Lei n. 8.666/93.

Nesse sentido, o Ministro Herman Benjamin firmou o seguinte entendimento, em julgamento de Recurso Especial 1.505.356 - MG, que se trata originariamente de ação de improbidade administrativa, entre o município Visconde do Rio Branco e o Ministério Público do estado.

AÇÃO CIVIL PÚBLICA - IMPROBIDADE ADMINISTRATIVA - CONTRATAÇÃO DE SERVIÇOS ADVOCATÍCIOS E INEXIGIBILIDADE DE LICITAÇÃO SINGULARIDADE DO SERVIÇO E NOTÓRIA ESPECIALIZAÇÃO - NÃO COMPROVAÇÃO DE ENRIQUECIMENTO ILÍCITO E PREJUIIZO AO ERÁRIO - ATO DE IMPROBIDADE NÃO EVIDENCIADO.

Como se sabe, o STJ tem entendido que "A contratação de profissionais da advocacia pela Administração Pública, mediante procedimento de inexigibilidade de licitação, deve ser devidamente justificada, como exige o art. 26 da Lei n. 8.666/93, com a demonstração de que os serviços possuem natureza singular, bem como com a indicação dos motivos pelos quais se entende que o profissional detém notória especialização" (AgRg no REsp 1273907/RS, Rel. Ministro HUMBERTO MARTINS, SEGUNDA TURMA, julgado em 18/06/2014, DJe 01/07/2014).

Além disso, esta Corte tem decidido que a conduta do Administrador Público de contratar serviços técnicos sem prévio procedimento licitatório e de não formalizar processo para justificar a inexigibilidade da licitação fere o art. 26 da Lei de Licitação e atenda contra o principio da legalidade que rege a Administração Pública, o que justifica a incidência do art. 11 da 8.429/1992. [...] (RECURSO ESPECIAL $\mathrm{N}^{\mathrm{o}}$ 1.505.356-MG, Rel. Ministro HERMAN BENJAMIN, SEGUNDA TURMA) 
Outro ponto de extrema relevância enquadra-se em relação à contratação de advogados estranhos aos quadros da Administração Pública. Cumpre ressaltar que a advocacia pública é uma atividade prestada por servidores públicos, de preferência aprovados em concurso público, conforme inciso II do art. 37 da Constituição Federal, função de confiança, inciso V do art. 37 do mesmo diploma legal, ou, até mesmo, para atendimento de excepcional interesse público, segundo inciso IX do art. 37, da Constituição Federal. (NIEBUHR, 2015, p. 177)

Contudo, dentro da Administração Pública existem entidades que já constituem corpo jurídico e outras que não, por isso a contratação de serviços jurídicos de terceiros requer certa atenção.

Caso a entidade possua corpo jurídico somente será licito contratar em casos excepcionais, verdadeiramente singulares, que fogem do padrão normal das causas e assuntos tratados ordinariamente por seus procuradores.

Nesse sentido, Maria Sylvia Zanella Di Pietro (1999, p. 293 apud NIEBUHR, 2015, p. 178):

É evidente que, dispondo o Município de corpo de Procuradores com competência específica para a cobrança da dívida ativa, a contratação de terceiros tem que ser devidamente justificada e analisada em cada caso. Os serviços rotineiros, como a cobrança da dívida ativa, não podem ser objeto de contrato de locação de serviços, já que correspondem a função permanente do Município, que dispõe de um quadro também permanente de advogados para desempenhá-la. Excepcionalmente, a Administração Pública pode defrontar-se com ação de especial complexidade, envolvendo tese jurídica inovadora, ou de considerável relevância para os cofres públicos; nesses casos, em se tratando de serviço de natureza singular, pode preferir contratar advogado de sua confiança e notoriamente especializado, valendo-se da inexigibilidade de licitação, com base no art. 25, II, da Lei n. 8.666/93. 
Sobre o tema dispõe, Marcos Juruena Villela Souto (1999, p. 277 apud NIEBUHR, 2015, p. 178):

Há situações em que mesmo não havendo uma anormalidade - o serviço inédito, singular ou a intervenção nos jurídicos das estatais sob alegação de corporativismo - pode ocorrer a necessidade legitima de contratação de advogados externos. É o caso, por exemplo, de uma elevação de carga de trabalho muito superior à possibilidade de atendimento por meios próprios do corpo jurídico existente (ex: aumento das reclamações trabalhistas) ou do impedimento de todos os profissionais envolvidos (numa demanda salarial contra a entidade pagadora). São hipóteses em que mesmo o serviço comum poderia justificar a contratação.

Por outro lado, diante das entidades que não possuem corpo jurídico, não há o que se objetar a contratação de terceiros para a prestação de serviços jurídicos. Como não há quem represente os interesses dessas entidades, é imperativo que elas contratem terceiros, estranhos aos seus quadros, sob a condição de prejuízo ao interesse público. (NIEBUHR, 2015, p. 179)

\section{CONCLUSÃO}

O Brasil como um todo passa por um momento conturbado tanto político, econômico e socialmente, o qual diante da globalização e de severos problemas de ordem social provocou a formação de gerações de jovens e adultos que cresceram em uma sociedade carente de informação e que buscam desordenadamente o poder pelo poder e pela garantia de privilégios pessoais.

Diante desse cenário político-administrativo conturbado pela corrupção em vários níveis da sociedade. O estudo de toda e qualquer prática administrativa que tenha como objetivo o interesse público deve ser analisado. Escuta-se de tanta fraude em processo licitatório, de lavagem de dinheiro, obras superfaturadas, que é necessário saber e entender mais sobre a licitação pública. 
A Lei de Licitações é responsável pela regularização de toda e qualquer contratação de serviço, obra ou materiais, ou seja, o procedimento licitatório é a regra, somente em casos previstos em seus dispositivos que ela será afastada. Nesse sentido, torna-se de extrema importância que sejam observados todos os requisitos presentes nos dispositivos do diploma legal, de modo que, não tenha, de modo algum, infringência de algum princípio do processo licitatório.

Nesse sentido, a pesquisa realizada, pôde-se concluir que, embora a contratação sem procedimento licitatório seja ambígua e ponha em ênfase a questão do princípio da moralidade e legalidade, deve ser levado em conta que, o administrador público constitui do conjunto de princípios norteadores, tanto da Administração Pública quanto do procedimento licitatório, presentes na Lei n. 8.666/93 e que combinados com a discricionariedade do administrador farão a escolha de melhor vantagem para o interesse público.

Segundo a doutrina pátria, pode-se obter o melhor entendimento acerca da inexigibilidade de licitar. Não somente é pensado na inviabilidade do objeto, ou seja, a impossibilidade de qualificar dois concorrentes. Mas também, no princípio da economicidade, de analisar a melhor opção, a menos onerosa.

Entende-se que, para o administrador a verificação do preço, nem sempre vale a pena, em relação à qualidade do produto ou durabilidade, dependendo do caso concreto.

A Lei de Licitações, em seu corpo legislativo, é possível compreender quais situações são passíveis da inexigibilidade e quais os requisitos que tornam o objeto da licitação inexigível.

Ainda, ressalva que, não somente deverão ser cumpridos os requisitos presentes no art. 13 da Lei n. 8.666/93, como a notória especialização e o serviço singular, mas também, a justificativa da escolha, como fica disposto no art. 26. Tudo deve ser 
minuciosamente descrito, afinal de contas, trata-se de interesse público e o mesmo, deve estar em primeiríssimo lugar quando se tratar de licitar.

\section{REFERÊNCIAS}

BANDEIRA DE MELLO. Celso Antônio. Curso de direito administrativo. São Paulo: Malheiros, 2015.

BATISTA, Leonardo Silva. Dispensa de licitação:uma exegese principiológica do instituto da contratação direta. In: Conteúdo Jurídico, São Paulo, jul. 2011. Disponível em: http://www.conteudojuridico.com.br/artigo,dispensa-de-licitacao-uma-exegese-principiologica-do-instituto-da-contratacao-direta,32779.html. Acesso em: 10 abr. 2017.

BRASIL. Constituição da República Federativa do Brasil.1988. São Paulo: Saraiva, 2012.

BRASIL. Lei complementar n. 8.666, de 21 de junho de 1993. Regulamenta o art. 37, inciso XXI, da Constituição Federal, institui normas para licitações e contratos da Administração Pública e dá outras providências. Disponível em:HTTP://www.planalto.gov.br/ccivil_03/leis/L8666cons.htm. Acesso em: 22 jul. 2016.

BRASIL. Superior Tribunal de Justiça. Resp n. 1.203.203 - GO. ADMINISTRATIVO E PROCESSUAL CIVIL. RECURSOS ESPECIAIS. AÇÃO CIVIL PÚBLICA. IMPROBIDADE ADMINISTRATIVA. CONTRATAÇÃO DE SERVIDORES SEM CONCURSO PÚBLICO. LEI PERMISSIVA, CUJA VOTAÇÃO NÃO OBEDECEU ÀS REGRAS DA CÂMARA MUNICIPAL, QUE PADECE DE INCONSTITUCIONALIDADE FORMAL E MATERIAL. CONTRATAÇÃO DE ADVOGADO SEM LICITAÇÃO. AUSÊNCIA DE HIPÓTESE DE INEXIGIBILIDADE DE LICITAÇÃO. PREMISSAS FÁTICAS QUE NÃO PODEM SER REVISTAS EM SEDE DE RECURSO ESPECIAL. SÚMULA N. 7 DO STJ. DESPROPORCIONALIDADE NA CONDENAÇÃO À PENA DE RESSARCIMENTO. ANÁLISE OBRIGATÓRIA A RESPEITO DA EXISTÊNCIA DE DANO AO ERÁRIO. VIOLAÇÃO DO ART. 535 DO CPC CARACTERIZADA. Disponível em: https:/ww2.stj.jus.br/processo/ revista/documento $/$ mediado $/$ componente $=$ ATC\&sequencial $=30457241 \&$ num_registro $=201001287920 \&$ data $=20130926 \&$ tipo $=91 \&$ formato $=$ PDF Acesso em: 15 maio 2017.

BRASIL. Superior Tribunal de Justiça. REsp n. 861566 - GO. PROCESSUAL CIVIL. ADMINISTRATIVO. AÇÃO CIVIL PÚBLICA. LEGITIMIDADE ATIVA DO MINISTÉRIO PÚBLICO. ART. 129, III, DA CONSTITUIÇÃO FEDERAL. EX-PREFEITO. ATO DE IMPROBIDADE ADMINISTRATIVA. CONTRATAÇÃO DE ADVOGADO. INEXIGIBILIDADE DE LICITAÇÃO. COGNIÇÃO DE MATÉRIA FÁTICA. SÚMULA 07/STJ. AUSÊNCIA DE DANO AO ERÁRIO. APLICAÇÃO DAS PENALIDADES. PRINCÍPIO DA PROPORCIONALIDADE. MULTA. Disponível em: https://ww2.stj.jus.br/processo/revista/documento/mediado/?componente=ATC\&sequencial $=3458548 \&$ num_registro $=200601194065 \&$ data $=20080423 \&$ tipo $=91 \&$ formato $=\mathrm{PDF}$

Acesso em: 14 maio 2017. 
BRASIL. Superior Tribunal de Justiça. REsp 848549 - MG. CRIMINAL. RESP. CRIME COMETIDO POR PREFEITO. COMPETÊNCIA ORIGINÁRIA DO TRIBUNAL DE JUSTIÇA. REJEIÇÃO DA DENÚNCIA. CONTRATAÇÃO DE ADVOGADO PELO MUNICÍPIO. INEXIGIBILIDADE DE LICITAÇÃO. UTILIZAÇÃO INDEVIDA DE SERVIÇO PÚBLICO. AUSÊNCIA DE DOLO. NÃO DEMONSTRAÇÃO. RECURSO PROVIDO. Disponível em: https://ww2.stj.jus.br/processo/revista/documento/ mediado/?componente $=$ ATC\&sequencial $=2761670 \&$ num_registro $=200600689902 \&$ data $=20070205 \&$ tipo=51\&formato=PDF Acesso em: 15 maio 2017.

BRASIL. Superior Tribunal de Justiça. REsp n. 915881 - SP. PROCESSUAL CIVIL E ADMINISTRATIVO - AÇÃO CIVIL PÚBLICA - IMPROBIDADE ADMINISTRATIVA - CONTRATAÇÃO SEM LICITAÇÃO - LEGITIMIDADE ATIVA DA PREFEITURA MUNICIPAL - COISA JULGADA - FUNDAMENTO INATACADO - INCIDÊNCIA DA SÚMULA 283/STF - JULGAMENTO ANTECIPADO DA LIDE - CERCEAMENTO DE DEFESA NÃO-CONFIGURADO - INEXIGIBILIDADE DA LICITAÇÃO - SINGULARIDADE DA NATUREZA DO SERVIÇO PRESTADO - SÚM. 7/STJ - LEI 8.429/1992 - OFENSA AOS PRINCÍPIOS DA ADMINISTRAÇÃO PÚBLICA - DESNECESSIDADE DE DANO MATERIAL AO ERÁRIO. Disponível em: https:/ww2.stj.jus.br/processo/revista/documento/mediado/?componente $=$ ATC \&sequencial $=5527776 \&$ num_registro $=200700024915 \&$ da$\mathrm{ta}=20090806 \&$ tipo $=51 \&$ formato=PDF Acesso em: 10 maio2017.

BRASIL. Superior Tribunal de Justiça. REsp n. 1.200.379 - MG. CONSTITUCIONAL - ADMINISTRATIVO - AÇÃO CIVIL PÚBLICA POR IMPROBIDADE ADMINISTRATIVA - CONTRATAÇÃO DE ADVOGADO POR NOTÓRIA ESPECIALIZAÇÃO - ART. 25 DA LEI N. ${ }^{\circ} 8.66693$ - INOBSERVÂNCIA DO PROCEDIMENTO DE FORMALIZAÇÃO DA DISPENSA - ART. 26 DA LEI DE LICITAÇÕES - OFENSA AO PRINCÍPIO DA LEGALIDADE - FIXAÇÃO DAS SANÇÕES - PROPORCIONALIDADE - PROCEDÊNCIA DO PEDIDO DE CONDENAÇÃO AO PAGAMENTO DE MULTA. Disponível em: https:// ww2.stj.jus.br/processo/revista/documento/mediado/?componente=ATC\&sequencial $=31408444 \&$ num_registro $=201001183589 \&$ data $=20131023 \&$ tipo $=91 \&$ formato=PDF Acesso em: $1 \overline{6}$ maio 2017.

BRASIL. Superior Tribunal de Justiça. REsp n. 1.505.356 - MG, ADMINISTRATIVO E PROCESSUAL CIVIL. ACÓRDÃO RECORRIDO. PUBLICAÇÃOANTERIOR ÀVIGÊNCIA DO NOVO CPC. REPERCUSSÃO GERAL DA MATTÉRIA PELOSUPREMO TRIBUNAL FEDERAL. SOBRESTAMENTO. DESNECESSIDADE.DIVERGÊNCIA JURISPRUDENCIAL DEMONSTRADA. IMPROBIDADE ADMINISTRATIVA.CONTRATAÇÃO DIRETA DE SERVIÇO DE ADVOCACIA PELO MUNICÍPIO. AUSÊNCIADE PREJUÍZO NO CASO CONCRETO. VIOLAÇÃO DOS ARTS. $3^{\circ}$, 13 E 25 DA LEIDE 8.666/93 E 11 DA LEI DE 8.429/92. EXECUÇÃO DOS SERVIÇOSCONTRATADOS. APLICAÇÃO DE MULTA CIVIL EM PATAMAR MÍNIMO. Disponível em: https:/ww2.stj.jus.br/processo/revista/ inteiroteor/?num_registro $=201303528142 \& d t \_$publicacao $=30 / 11 / 2016$ Acesso em: 17 maio 2017.

BRASIL. Supremo Tribunal Federal. Inq n. 3.074 - SC. EMENTA: IMPUTAÇÃO DE CRIME DE INEXIGÊNCIA INDEVIDA DE LICITAÇÃO. SERVIÇOS ADVOCATÍCIOS. REJEIÇÃO DA DENÚNCIA POR FALTA DE JUSTA CAUSA. Disponível em: http://redir.stf.jus.br/paginadorpub/paginador.jsp?docTP=TP\&docID $=6849679$ Acesso em: 30 jun. 2017. 
BRASIL. Tribunal de Contas da União. TC 004.948/95-5/MG. Auditoria. CVRD. Licitação. Não justificação em ata do motivo da inabilitação do licitante. Falta de planejamento das compras. Dispensa e inexigibilidade de licitação não justificada. Contratação direta com fundamento na inexigibilidade de licitação. Determinação. - Inexigibilidade de licitação. Considerações sobre a matéria. Relator: Min. Bento José Bugarin. Decisão 613/96. Disponível em: http://www.tcu.gov.br/Consultas/Juris/Docs/judoc\%5CDec\%5C19980109\%5CGERADO_TC-20338.pdf.Acesso: 05 maio 2017.

CARVALHO FILHO, José dos. Manual de direito administrativo: revista, ampliada e atualizada até 31-12-2012. 26. ed. São Paulo: Atlas, 2013.

CARVALHO, Marcelo. A notória especialização como fundamento para inexigibilidade da licitação. In: Assembléia Legislativa São Paulo.[20?0]. Disponível em: http:// www.al.sp.gov.br/repositorio/bibliotecaDigital/478_arquivo.pdf. Acesso em: 24 nov. 2016.

CRETELLA JUNIOR, José. Curso de direito administrativo. 4. ed. Rio de Janeiro: Editora Forense, 1975.

DAFT, Richard L. Administração. São Paulo: Cengage Learning, 2010.

DI PIETRO, Maria Sylvia Zanella. Direito administrativo. 14. ed. São Paulo: Atlas, 2002.

DI PIETRO, Maria Sylvia Zanella.Direito administrativo. 22. ed. São Paulo: Atlas, 2009.

DI PIETRO, Maria Sylvia Zanella. Direito administrativo. 23. ed. São Paulo: Atlas, 2010.

FIGUEIREDO, Lúcia Valle. FERRAZ, Sérgio. Dispensa e inexigibilidade de licitação. 3. ed. São Paulo: Malheiros, 1994).

GASPARINI, Diógenes. Direito administrativo. 8. ed. São Paulo: Saraiva, 2003.

JACOBY FERNANDES, Jorge Ulysses. Contratação direta sem licitação: dispensa de licitação: inexigibilidade de licitação: procedimentos para a contratação sem licitação; justificativa de preços; inviabilidade de competição; emergência; fracionamento; parcelamento; comentários às modalidades de licitação, inclusive o pregão: procedimentos exigidos para a regularidade da contratação direta. Belo Horizonte: 10. ed. Fórum, 2016.

JUSTEN FILHO, Marçal. Comentários à lei de licitações e contratos administrativos.16. ed. São Paulo: Revista dos Tribunais, 2014.

JUSTEN FILHO, Marçal. Curso de direito administrativo. 4. ed. São Paulo: Saraiva, 2009.

MACHADO, Antônio Cláudio da Costa (org.), FERRAZ, Anna Candida da Cunha (coord.). Constituição interpretada: artigo por artigo. 3. ed. Barueri: Manole, 2012.

MARTINES JÚNIOR, Eduardo. Licitação e sua inexigibilidade na contratação de serviços advocatícios pelo poder público. Revista de Direito Constitucional e Internacional, v. 47, abr./jun. 2004. Disponível em: http://www.revistadostribunais.com. $\mathrm{br} / \mathrm{maf} / \mathrm{app} / \mathrm{resultList} /$ document? \&src=rl\&srguid=i0ad82d9a0000015bff269f4850a55d47\&docguid=I6620b0b0f25311dfab6f010000000000\&hitguid=I6620b0b0f- 
$25311 \mathrm{dfab} 6 \mathrm{f} 010000000000 \&$ spos $=1 \&$ epos $=1 \& \mathrm{td}=492 \&$ context $=8 \&$ crumb $=$-actionappend\&crumb59label=Documento\&isDocFG $=$ false\&isFromMultiSumm $=\&$ startChunk=1\&endChunk=1. Acesso em: 09 maio 2017.

MEIRELLES, Hely Lopes. Licitação e contrato administrativo.12. ed. São Paulo: Malheiros, 1999.

MEIRELLES, Hely Lopes. Direito administrativo brasileiro. 23. ed. São Paulo:Malheiros, 1998.

MEIRELLES, Hely Lopes. Direito administrativo brasileiro. 36. ed. São Paulo: Malheiros, 2010.

NIEBUHR, Joel de Menezes. Dispensa e inexigibilidade de licitação pública. 4. ed. Belo Horizonte: Fórum, 2015.

RIGOLIN, Ivan Barbosa; BOTINO, Marco Tullio. Manual prático das licitações. São Paulo: Saraiva, 1995.

SANTOS, Márcia Walquiria Batista dos; CARRIJO, Maria Tereza Dutra. Licitações e contratos - roteiro prático. 2. ed. São Paulo: Malheiros, 2001.

ROSA, Márcio Fernando Elias. Direito administrativo. 5. ed. São Paulo: Saraiva, 2003.

VELLOSO, Carlos Mário da Silva. Advogado: contratação - serviços técnicos especializados - inexigibilidade de licitação. Migalhas. 2016. Disponível em: http://www. migalhas.com.br/arquivos/2016/8/art20160824-02.pdf. Acesso em: 12 nov.2016.

Recebido em: 30/04/2019

Aprovado em: 10/06/2019 